\title{
EL CASO FORTUITO EN LA RESPONSABILIDAD CIVIL EXTRACONTRACTUAL
}

\author{
Act of God in Tort Law
}

\author{
LILIAN C. SAN MARTín NEIRA ${ }^{1}$ \\ Universidad Alberto Hurtado
}

\section{RESUMEN}

\begin{abstract}
En este artículo se postula que el rol del caso fortuito en la estructura de la responsabilidad extracontractual es tributario de la relación funcional entre culpa y causalidad. Así, en casos de responsabilidad subjetiva, la presencia de caso fortuito excluye la culpa y, en consecuencia, la causalidad. Tratándose de hipótesis de responsabilidad objetiva, dado que la culpa no cumple ningún rol en el juicio de atribución de responsabilidad, el caso fortuito excluye directamente la causalidad.
\end{abstract}

\section{PALABRAS CLAVE}

Caso fortuito o fuerza mayor, causalidad, culpa

\section{ABSTRACT}

This article postulates that the role of the act of God in Tort Law depends on the functional relationship between negligence and causation. Thus, in cases of tort of negligence, the presence of an act of God excludes negligence and, consequently, causation. In the cases of strict liability, since negligence plays no role in the attribution of liability, the 'act of God' directly excludes causation.

\section{KEYWORDS}

Act of God or Force Majeure, Causation, Negligence

\section{Introducción}

En el año 2006 el profesor Barros afirma que el caso fortuito tiene escasa relevancia en la responsabilidad extracontractual por negligencia, pues pertenece especialmente al derecho contractual $^{2}$. Para entonces, tal afirmación prácticamente no admitía discusión. La literatura no era abundante y la jurisprudencia relativa al caso fortuito en su inmensa mayoría versaba sobre responsabilidad contractual. Hoy, en cambio, si se introduce la voz 'caso fortuito' en cualquier motor de búsqueda de jurisprudencia, una buena parte de los resultados son de responsabilidad extracontractual. Particularmente, se trata de casos en que el demandado invoca como caso fortuito la ocurrencia de un fenómeno natural extremo: terremoto, temporal, nevazón, aluvión, entre otros. Todos los cuales son de frecuente ocurrencia en nuestro país y cada vez originan más litigios ${ }^{3}$.

Frente a este nuevo escenario, vale la pena volver sobre el caso fortuito teniendo en cuenta los matices de la institución en la responsabilidad contractual y en la extracontractual. En efecto, a pesar de los esfuerzos por unificar ambos regímenes de responsabilidad, existen

\footnotetext{
${ }^{1}$ Profesora de Derecho Civil, Universidad Alberto Hurtado, Santiago, Chile, correo electrónico: Isanmar@uahurtado.cl. Este artículo forma parte del proyecto Fondecyt Regular № 1170686, del que la autora es investigadora responsable.

${ }^{2}$ BARROS (2006), p. 414. Si bien existe una segunda edición de esta obra, fue publicada cuando este trabajo estaba ya prácticamente concluido. Además, en un seminario sostenido en el mes de marzo en Concepción, el profesor Barros aclaró que en lo que atañe al caso fortuito sustancialmente la obra ha permanecido invariada, con lo cual las sucesivas referencias serán todas a la primera edición.

${ }^{3}$ SAN MARTíN (2018), pp. 123 y ss.
} 
ámbitos donde se advierten diferencias conceptuales entre ellos, y el caso fortuito es uno de los puntos de separación. En la medida en que la responsabilidad contractual regla el incumplimiento de una obligación previamente contraída, es necesario hacer coherente el concepto de caso fortuito con el grado de diligencia exigible al deudor conforme al criterio de la utilitas contrahentium consagrado en el artículo 1547 C.C., así como con otros conceptos e instituciones destinadas a gobernar las consecuencias de los eventos sobrevenidos en la relación obligatoria, como son la imposibilidad sobrevenida de la prestación (en Chile, pérdida de la cosa debida), la excesiva onerosidad sobreviniente y la teoría de los riesgos. La situación es diversa en la responsabilidad extracontractual. Aquí las nociones referidas no resultan aplicables, porque no existe una prestación individualizada a la cual hacer referencia, sino un deber genérico de cuidado cuyos contornos precisos resultan establecidos a posteriori a través de la decisión judicial, y tampoco ha operado entre las partes una distribución negociada de los riesgos. Naturalmente, esto no obsta a que en muchos casos este deber haya sido establecido $a$ priori por disposiciones normativas explícitas, pero esta situación dista mucho de la noción de obligación y de la distribución contractual de los riesgos ${ }^{4}$.

Con todo, teniendo en cuenta las instituciones que no se intersecan con el concepto de caso fortuito en sede extracontractual, es posible sostener una hipótesis conceptual común para ambos regímenes de responsabilidad: el caso fortuito opera fuera de la órbita de la conducta que era jurídicamente exigible al demandado, en otras palabras, opera más allá del ámbito de riesgos atribuible a un sujeto determinado. Sin embargo, esta hipótesis no afirma nada sobre la construcción del ámbito de riesgo que debe ser cubierto. Esta construcción es diversa en sede contractual y extracontractual y, en esta última, es diversa según se trate de una responsabilidad subjetiva (o por culpa) u objetiva o estricta.

De acuerdo a la hipótesis presentada, el objetivo de esta investigación es analizar, dentro del marco de la responsabilidad extracontractual, la función que el caso fortuito cumple en la estructura del juicio de responsabilidad y el rol que en tal función les corresponde a la imprevisibilidad e irresistibilidad en cuanto elementos característicos ${ }^{5}$. Este objetivo equivale a preguntarse sobre las relaciones conceptuales que le corresponden al caso fortuito en cuanto eximente de responsabilidad. Se trata de saber si el caso fortuito excluye la culpa o la causalidad. Esta pregunta no es trivial. Por un lado, desde el punto de vista práctico, la respuesta condiciona la posibilidad de invocarlo en hipótesis de responsabilidad objetiva, así como la individualización de las reglas de prueba que son aplicables. Por otra parte, desde el punto de vista conceptual, la respuesta determina: (i) la sinonimia (o no) entre el caso fortuito y la fuerza mayor; y (ii) las relaciones lógicas entre las nociones de imprevisibilidad e irresistibilidad.

En las líneas que siguen se formulan respuestas para estas tres cuestiones, aunque no necesariamente en ese orden. A partir de estas respuestas, queda demostrado que el concepto de caso fortuito se relaciona con la culpa y con la causalidad de forma simétrica, porque su función principal es excluir la responsabilidad por hechos que quedan más allá del ámbito de riesgos que es atribuible al sujeto y que ha sido determinado, en primer lugar, por la culpa, en tanto norma general y supletoria de responsabilidad, y, en su caso, conforme a las disposiciones normativas que reglan hipótesis de responsabilidad objetiva. Estas conclusiones son el fruto de un acucioso análisis doctrinario y jurisprudencial. Sin embargo, en razón de la extensión limitada, el texto se centra fundamentalmente en el análisis doctrinario, realizando un reenvío general a

\footnotetext{
${ }^{4}$ BARROS (2006), pp. 975 y ss.; SCHOPF (2017), pp. 61 y ss.

${ }^{5}$ Aunque un sector de la doctrina nacional coincide en torno a que el caso fortuito exige también la "exterioridad" (por todos, BRANTT (2009), pp. 39-102; BRANTT (2010), pp. 51 y ss., TAPIA (2019), p. 117 y ss.), el análisis se limita a la imprevisibilidad e irresistibilidad por tres órdenes de razones: (i) porque constituyen los únicos requisitos enunciados en la definición legal de la institución; (ii) porque corresponden a los elementos que tradicionalmente han configurado la eximente caso fortuito o fuerza mayor, desde el derecho romano en adelante; y (iii) porque si bien la exterioridad resulta didácticamente útil para explicar que el hecho no puede deberse a un riesgo que el deudor (en sentido técnico) deba soportar, lo cierto es que esta utilidad se difumina, en la medida en que, tal y como espero demostrar en lo sucesivo, es justamente en esa dirección que apuntan las exigencias clásicas de hecho imprevisto e irresistible.
} 
las sentencias analizadas, con el único objeto de sustentar las conclusiones alcanzadas y guiar al lector en la consulta de la jurisprudencia relevante.

Para lograr el objetivo propuesto, en lo sucesivo el texto será dividido en tres partes: La definición legal de caso fortuito; La relación entre caso fortuito y ámbito de riesgos; y La resistibilidad como elemento del caso fortuito. Para terminar con un cuerpo de Conclusiones.

\section{La definición legal de caso fortuito}

Según el artículo 45 C.C., "se llama fuerza mayor o caso fortuito el imprevisto a que no es posible resistir, como un naufragio, un terremoto, el apresamiento de enemigos, los actos de autoridad ejercidos por un funcionario público, etc.". El carácter imprevisto e irresistible del evento aparecen, por tanto, como dos requisitos independientes y copulativos de la institución. Se origina así la duda respecto de aquellos eventos que pueden en cierta medida anticiparse, pero que el demandado no estaba en posición de evitar o, del lado contrario, eventos que, de haberse previsto, habrían podido incluso fácilmente evitarse o, cuando menos, ponerse a resguardo de ellos eludiendo el daño subsecuente. Estas cuestiones, a su turno, se relacionan con la sinonimia entre caso fortuito y fuerza mayor admitida por el Código de Bello, asunto que tiene un importante trasfondo histórico, pues, como reconoce la doctrina nacional, originalmente se trató de dos conceptos diferenciados ${ }^{6}$.

En efecto, a partir de las fuentes romanas, es posible sostener que la fuerza mayor, correspondiente a la noción de vis maior, alude a una fuerza 'irresistible' y 'externa', el caso fortuito, correspondiente al casus, alude a la ausencia de culpa ${ }^{7}$. Así las cosas, ambos serían institutos liberadores de responsabilidad, pero el fundamento no era el mismo, pues no es lo mismo la ausencia de culpa (casus), que la causa extraña (vis) ${ }^{8}$. En otras palabras, mientras que la vis maior tiene un valor semántico "positivo" (algo que ocurre), casus tendría negativamente un significado, $a b$ origine, en el ámbito de figuras delictuales, alusivo a aquello que es accidental en cuanto involuntario, y en una fase siguiente, en el ámbito de las relaciones obligatorias ex contractu, a aquello que ocurre sin culpa ${ }^{9}$.

En lo que aquí importa, de esa distinción se sigue una consecuencia significativa, esto es, que el caso fortuito aludía al 'accidente' que no se podía prever ni resistir: justamente porque era 'imprevisible' excluía la culpa. Mientras que la fuerza mayor (vis maior o maior casus) aludía a un 'evento' que, aunque 'previsible', no podía resistirse (evitarse), justamente porque era ajeno al deudor, y originariamente no nace como una delimitación de la responsabilidad (praestare) del deudor, sino para agrupar una serie acontecimientos naturales y humanos inevitables, como un terremoto, la tempestad, la invasión de estorninos, el ataque de enemigos, los actos de autoridad, etc. ${ }^{10}$.

Bien vistas las cosas, atendido su carácter inevitable, los eventos constitutivos de vis maior también resultan incompatibles con la idea de culpa. Como afirma Cardilli, la 'fuerza mayor' es siempre 'caso fortuito' ${ }^{11}$. La explicación radica en la estructura de la culpa que, además de la

\footnotetext{
${ }^{6}$ Si bien no se le asigna ninguna relevancia práctica, pues se acepta la sinonimia, la doctrina chilena tradicionalmente ha enseñado que la fuerza mayor corresponde a un hecho que proviene de la actividad humana, como un acto de autoridad, mientras que el caso fortuito proviene de un acto de la naturaleza. CLARO (2015), p. 145. Esta distinción tiene asidero en la historia de la norma, cuya primera versión agregaba: "el caso fortuito se llama fuerza mayor cuando consiste en un hecho del hombre, como en los dos últimos ejemplos" (BELLO (1890), p. 11; BARRIENTOS (2016), p. 189. Con todo, como se aprecia fácilmente de la lectura del texto, la intención del legislador no era dar un contenido sustancialmente diverso a ambas instituciones. Por lo demás, la identidad entre ellas estaba presente desde el primer proyecto de Código, el cual, en lo que constituye la versión preliminar del actual artículo 1547, contenía la frase "la denominación de caso fortuito comprende la fuerza mayor". Expresión que se mantuvo inalterada hasta la introducción de la definición del artículo 45 en sede de comisión revisora (BARRIENTOS (2016), p. 188). De ahí que la doctrina afirme que en Chile no se siguen consecuencias de tal distinción, sino que, al contrario "para el derecho designan la misma idea". CLARO (2015), p. 145; TAPIA (2013), pp. 35 y ss.

${ }^{7}$ Véanse los casos contemplados en D.13.6.18, pr.; D.16.3.1.35, D.47.9.9; D.50.17.23.

${ }^{8}$ FRANCO (2009), pp. 4 y ss.

${ }^{9}$ CARDILLI (1996), pp. 81-82.

${ }^{10}$ CARDILLI (1995), pp. 474 y ss.; CARDILLI (1996), p. 81.

${ }^{11}$ CARDILLI (1996), p. 81
} 
previsibilidad del daño, exige la posibilidad de adecuar la conducta para prevenir su ocurrencia ${ }^{12}$, la cual queda excluida frente a la 'inevitabilidad' del hecho. Así, una vez generalizada la idea de que la culpa está a la base de responsabilidad (contractual y extracontractual), pues no hay responsabilidad sin culpa, tanto el casus como la vis llevan al mismo resultado: en presencia de ellos no es posible achacar responsabilidad al demandado porque falta la culpa. Este resultado práctico fue el que consintió la fusión de ambos conceptos, que probablemente comenzó con Salvio Juliano ${ }^{13}$ y se consolidó con los juristas del Derecho intermedio ${ }^{14}$. Sin embargo, esta fusión no fue unívoca, pues dio lugar a dos lecturas de la institución.

En una primera lectura, la estructura de la fuerza mayor primó por sobre la de caso fortuito, de manera que la 'irresistibilidad' o 'inevitabilidad'15 pasó a ser el elemento determinante de la institución ${ }^{16}$. En este sentido, en el comentario de Vinnio se lee: "Ilamamos caso fortuito aquel que no puede preverse humanamente, o que aun cuando pueda preverse no puede resistirse" ${ }^{17}$. Asimismo, en el comentario de García Goyena al Proyecto español de 1851, se lee: "Casos fortuitos son los que no pudieron preverse, ó previstos no pudieron evitarse" ${ }^{18}$. A nivel legislativo, como ejemplos de ordenamientos que recogen esta afirmación, pueden citarse los códigos civiles argentino ${ }^{19}$, brasileño ${ }^{20}$ y español ${ }^{21}$. Todos los cuales contemplan a la 'inevitabilidad' como el rasgo determinante de la institución.

En una segunda lectura, se fusionaron los requisitos básicos de ambas figuras, de modo que son necesarias tanto la imprevisibilidad como la irresistibilidad. Así, en el Diccionario Razonado de Legislación y Jurisprudencia de Joaquín Escriche, probable fuente del artículo 45 del Código de Bello22, se define al caso fortuito como "El suceso inopinado, ó la fuerza mayor que no se puede prever ni resistir" ${ }^{23}$. Esta visión fue la acogida en el Derecho francés, cuyo código civil, en su versión vigente hasta 2016, empleaba conjunta o indistintamente las expresiones caso fortuito y fuerza mayor ${ }^{24}$. Aunque el texto legal nada decía al respecto, la doctrina tradicional francesa estaba conteste en que eran necesarias tanto la imprevisibilidad

\footnotetext{
${ }^{12}$ Ampliamente sobre el tema, SAN MARTín (2018), pp. 557 y ss.

13 CARDILLI (1995), p. 475; CARDILLI (1996), p. 81

${ }^{14}$ Varios de los pasajes relativos a la vis maior aluden a la responsabilidad del comodatario (por ejemplo, D.13.6.18, pr.; D.44.7.1.4). Ahora bien, en estricto rigor, el hecho de que estos eventos excluyan la responsabilidad del comodatario no se debe a su ausencia de culpa, pues originariamente su responsabilidad no estaba delimitada por la culpa, sino por la 'custodia' (ampliamente sobre este tema CANNATA (1996), p. 52 y ss.; SERRANO-VICENTE (2006), p. 173 y ss.). La supresión de la alusión a la custodia y su reemplazo por la noción de "exactísima diligencia" en la compilación justinianea permitió a los autores medievales la fusión definitiva de los conceptos de fuerza mayor y caso fortuito como excluyentes de la culpa. La consolidación de esta idea es claramente apreciable en las Siete Partidas donde, aludiendo a la responsabilidad del comodatario se sostiene que este no responde de la pérdida de la cosa si ella acontece sin su culpa y luego, como ejemplos de ausencia de culpa, menciona una serie de eventos que en el Corpus luris se adscriben a 'fuerza mayor'. Véase P.5a , tit. 2. Ley 3a .

${ }^{15}$ En Chile, Brantt afirma que el empleo del verbo "resistir", en lugar de "evitar" en el artículo 45 C.C. indica que la norma alude a las consecuencias y no al hecho en sí mismo (BRANTT (2010), pp. 145 y ss.). Sin embargo, en las fuentes clásicas y medievales se emplean indistintamente los verbos 'resistir' e 'impedir', que luego fueron traducidas al castellano con alusión a 'resistir' o bien a 'evitar', sin uniformidad de criterios. Dado este uso intercambiable de 'resistir' y 'evitar' en la doctrina consultada por Bello, no parece que haya bases suficientes para extraer una conclusión semejante. Así las cosas, en este punto, concuerdo con Tapia en cuanto a que parece perfectamente posible que la resistibilidad aluda tanto al hecho en sí mismo, como a sus consecuencias. TAPIA (2013), pp. 89 y ss.

${ }^{16}$ Esta es la visión mayoritaria, al punto que Barrientos sostiene que "este carácter de imposibilidad de resistir o inevitabilidad fue el quicio sobre el cual giró la noción de caso fortuito en todo el derecho común". BARRIENTOS (2016), p. 189.

${ }_{17}$ VINNIO, (1847), p. 127. En un sentido idéntico afirma Donello "Casus fortuitus a nostris definitur, casus qui praevederi non potest, aut cui preaviso resisti non potest (...) Idem dicittur generaliter vis maior: ut sit vis maior quam ut ei resisti possit". DONELLI (1764), col. 655. Asimismo, Ferraris, quien afirma "Casus vero est rei inopinatae eventos, qui neque ab homine diligentissimo praevideri, vel impedire potest: unde de casu fortuito, ut de terraemotu, rapina, impetu praedonum, grandine, fulmine et similibus damnum causantibus, nemo tenetur, quia est extrahuma providentiam". FERRARIS (1861), col. 1331, nota 7.

${ }^{18}$ Comentario al artículo 1014 del Proyecto de 1851. GARCíA (1852), p. 49.

${ }^{19}$ Artículo 1730, que sustancialmente reproduce el artículo 514 del Código anterior.

${ }^{20}$ Artículo 393.

${ }^{21}$ Artículo 1105.

22 BARRIENTOS (2016), p. 189; AMUNATEGUI (2019), p. 45. De último sobre las razones que llevaron al legislador nacional a preferir la definición de Escriche por sobre otras disponibles a la época de la codificación, DE NARDI (2019), pp. 59-78.

${ }^{23}$ ESCRICHE (1831), pp. 228-229.

${ }^{24}$ En consecuencia, la doctrina francesa tradicional estaba conteste en la sinonimia (MAZEAUD et al. (1960), p. 319; SAVATIER (1939), p. 227), sin perjuicio de que esta idea mudó radicalmente. Una descripción detallada sobre esta evolución conceptual y sus consecuencias, puede verse en MUNITA (2014), pp. 393 y ss.
} 
como de la irresistibilidad. En este sentido, afirman los Mazeaud que "un caso de fuerza mayor es un acontecimiento anónimo, imprevisible e irresistible" ${ }^{25}$. En la doctrina francesa moderna, en cambio, coherentemente con la preponderancia de la noción de fuerza mayor por sobre la de caso fortuito, el requisito de la previsibilidad fue sometido a duros cuestionamientos, pero, al parecer, ha primado la idea de que sí es necesario ${ }^{26}$.

A la luz del artículo 45 C.C., es claro que en Chile se optó por la segunda lectura de la institución, aunque con una importante variación: no habla 'imprevisible', sino de 'imprevisto'. Así las cosas, el Código de Bello hace expresamente sinónimos las expresiones fuerza mayor y caso fortuito, como una sola eximente, que para configurarse requiere copulativamente del carácter 'imprevisto' del hecho y de su 'irresistibilidad'. En el siguiente apartado intentaremos explicar cómo han de ser entendidos estos requisitos.

\title{
La relación entre caso fortuito y ámbito de riesgos
}

\author{
La importancia del estándar de cuidado en la construcción del caso fortuito. La noción \\ de "imprevisto"
}

Al analizar los requisitos impuestos por el legislador para la configuración de la eximente en análisis, lo primero que cabe destacar es que la norma no alude al hecho "imprevisible", sino al "imprevisto". Sin embargo, uniformemente la doctrina y la jurisprudencia aluden a la 'imprevisibilidad', lo que ha llevado a no pocas confusiones ${ }^{27}$. Así, por ejemplo, bajo la premisa de que Chile es un país sísmico, se ha llegado a dudar de la posibilidad de que un terremoto de grado 8,8 pueda ser invocado como caso fortuito, pues es sabido que un evento de esas características 'puede' ocurrir ${ }^{28}$.

Llevado al extremo, podría decirse que en Chile prácticamente no hay evento sísmico imprevisible, por ende, un terremoto nunca sería una excusa válida como caso fortuito, para ninguna persona. Como se advierte fácilmente, esa forma de entender la institución lleva a que prácticamente no haya imprevistos y, por tanto, la exención de caso fortuito constituya 'letra muerta'. Tal interpretación debe, entonces, rechazarse y substituirse por una "cierta relatividad en la apreciación de los hechos" 29 , dependiendo del contexto en que se encuentra el sujeto concreto cuya conducta se juzga. Aquí radica la importancia de que el texto hable de 'imprevisto' y no 'imprevisible', pues de esta manera la norma relativiza la previsibilidad y permite relacionarla con el ámbito de riesgos atribuible al sujeto en particular, conforme a las circunstancias en que actúa, independizándola de las características objetivas del hecho.

Así las cosas, un mismo evento puede constituir caso fortuito para una persona y no para otra ${ }^{30}$. El terremoto del $27 \mathrm{~F}$ es un buen ejemplo, pues respecto de algunas personas se ha aceptado la defensa de caso fortuito, mientras que para otras no ha prosperado ${ }^{31}$. Asimismo, un evento correspondiente a una categoría abstracta de hechos puede constituir caso fortuito en

\footnotetext{
${ }_{25}$ MAZEAUD et al. (1960), p. 319. En sentido semejante SAVATIER (1939), p. 228; DELVINCOURT (1834), p. 159.

${ }^{26}$ En detalle sobre esta discusión MUNITA (2014), pp. 393 y ss.; BRUN (2015), pp. 261 y ss.

${ }^{27}$ En particular, la alusión a la imprevisibilidad llevó a establecer que el caso fortuito operaba respecto de eventos absolutamente extraordinarios, que ni el agente ni ninguna persona hubiera podido prever. Esta visión es fuertemente criticada por la doctrina moderna y puede decirse en gran medida superada. BRANTT (2010), pp. 123 y ss.; TAPIA (2013), p. 45 y ss.; TAPIA (2019), pp. 52 y ss.

${ }^{28}$ A modo de ejemplo, reportaje de la Revista del Abogado a propósito del terremoto de 27 de febrero de 2010 . COLEGIO DE ABOGADOS DE CHILE (2010), pp. 4 y ss.

${ }^{29}$ HINESTROSA (2007), p. 788.

${ }^{30}$ En este mismo sentido interpretamos las palabras de Corral, cuando, a propósito del terremoto de 27 de febrero de 2010 y el rubro de la construcción afirma: "la discusión se centrará en si la magnitud, la intensidad y la eficacia destructiva del sismo de febrero de 2010, debe ser considerado imprevisible para agentes profesionales de la Construcción, lo que será diferente según el lugar en que estaba emplazado el edificio". CORRAL (2010b), p. 465. Con todo, cabe señalar que este autor no especifica los criterios con arreglo a los cuales se juzgará la previsibilidad, limitándose a negar que se juzguen conforme a la diligencia debida por el demandado. CORRAL (2010b), p. 465, n. 16

31 Para una revisión en extenso de la jurisprudencia relativa al 27F véanse Ríos (2017); ALARCÓN y MUÑOZ (2018); FARFARELLO (2019); BARRÍA (2018) pp. 235-269, TAPIA (2019), pp. 139 y ss.
} 
unas circunstancias y no serlo en otras. La caída de un árbol en la carretera austral puede ser calificada de fortuito ${ }^{32}$, pero no así la caída de un árbol en la plaza de Concepción ${ }^{33}$. ¿Dónde radica la diferencia? La doctrina más reciente está conteste en que la diferencia está dada por el estándar de cuidado exigible al respectivo demandado. En este sentido, se afirma que la 'previsibilidad' no puede juzgarse en "términos absolutos, sino en relación a la diligencia debida por el agente y sus circunstancias" 34 , es decir, la "diligencia exigible ad casum" ${ }^{35}$. Ella dependerá del sujeto, del tipo de evento y de las circunstancias que lo rodean.

En síntesis, hay sujetos cuyo estándar de cuidado o diligencia implica contemplar la posible ocurrencia del hecho (caída del árbol) y actuar en consecuencia, pero hay otros sujetos cuyo estándar no alcanza ese nivel de precaución. Ahora bien, como es sabido, en la estructura de la responsabilidad civil, hablar de estándar de diligencia o cuidado equivale a hablar de culpa, pues es en este elemento donde se analiza el comportamiento del sujeto y se lo compara con aquel que jurídicamente estaba llamado a observar. Así ha sido desde el derecho romano en adelante. En consecuencia, atendido que el caso fortuito equivale a un hecho que está más allá de la diligencia exigible al sujeto ${ }^{36}$; él supone ausencia de culpa y su invocación sirve justamente para demostrar esta circunstancia. Existe, por tanto, una relación de continuidad entre el Código Civil y la tradición jurídica de la cual proviene el concepto.

En otro orden de idas, tales consideraciones permiten confirmar y apreciar la relevancia y alcance del hecho de que la definición aluda a 'imprevisto' y no a 'imprevisible'. Con ello se realiza un reenvío a la situación concreta y al tiempo en que el agente toma la decisión de actuar. El juicio de previsibilidad, por tanto, no es abstracto, sino situado en un sujeto, tiempo y lugar. Con todo, esto no significa que el legislador aluda exclusivamente a aquello que el demandado efectivamente previó, pues, por tratarse de una noción opuesta culpa, quedarán incluidos todos aquellos eventos potencialmente previsibles con la diligencia debida. Esto justifica el uso de la expresión 'imprevisibilidad' como requisito del caso fortuito. Por esta razón, a menos que se diga otra cosa, en lo sucesivo se emplearán las expresiones imprevisibilidad e imprevisto de manera intercambiable.

Finalmente, cabe señalar que, sin perjuicio de algunas disidencias ${ }^{37}$, ese ha sido el entendimiento de las principales obras sobre responsabilidad extracontractual chilenas. Así, Alessandri, señala que "el hecho debe ser imprevisto e irresistible en sí mismo, es decir, que ni el agente ni ninguna otra persona colocada en las mismas circunstancias de tiempo y lugar habría podido preverlo y resistirlo" (destacado nuestro) ${ }^{38}$. Como se aprecia, el autor contextualiza la ocurrencia del caso fortuito en las circunstancias de tiempo y lugar, es decir, lo relativiza con el estándar de la culpa 39 . Por su parte, Barros señala que "el caso fortuito tiene una relevancia más bien limitada en la responsabilidad extracontractual por negligencia. En efecto, la responsabilidad por culpa supone precisamente que el daño sea atribuible a negligencia y no a una causa extraña al demandado. En otras palabras, atribuir un hecho a fuerza mayor excluye imputarlo a culpa y viceversa" 40 .

\footnotetext{
${ }^{32}$ Corte Suprema, Rol № 2448-2010, de 12 de junio de 2013.

${ }_{33}$ Corte de Apelaciones de Concepción, Rol № 940-2007, de 8 de abril de 2008, confirmada en Corte Suprema, Rol № 3003-2008, de 4 de noviembre de 2008.

${ }^{34}$ TAPIA (2013), p. 53.

35 BASOZABAL (2015), p. 111.

${ }^{36}$ La contraposición entre caso fortuito (como act of God) y deber de cuidado o diligencia ha sido advertida también en la doctrina del Common Law. En tal sentido, luego de un acucioso análisis jurisprudencial, concluye Binder: "in conclusion, the act of God defense is a theory which no longer makes legal or factual sense. It is time to recognize that when looked at in the context of the specifics, the act of God defense is simply an application of normal negligence principles. Therefore, it should be incorporated into general negligence standards". BINDER (1996), p. 79.

37 PIZARRO (2005), p. 121. Asimismo, Corral, para quien en caso de la responsabilidad extracontractual el caso fortuito no excluye exactamente la culpa, sino la voluntad del hecho. CORRAL (2013), pp. 107 y ss. Empero, este mismo autor señala que, en la responsabilidad contractual, el caso fortuito excluye la causalidad, CORRAL (2010a), p. 132.

${ }^{38}$ ALESSANDRI (2005), p. 435.

${ }^{39}$ Este razonamiento se confirma cuando se aprecian los casos que el autor da como ejemplos de casos fortuitos, por contraposición a los que no lo constituyen, sin excepción, todos estos últimos son casos en que ha habido culpa. Véase ALESSANDRI (2005), p. 436. ${ }^{40}$ BARROS (2006), p. 414. En el mismo sentido, COUSTASSE e ITURRA (1958), p. 47; LETELIER (2001), p. 103; RODRÍGUEZ (2010), pp. 442 y ss.; TAPIA (2013), p. 20.
} 


\section{El caso fortuito como excluyente de la culpa y, en consecuencia, de la causalidad}

Llevado al extremo, que el caso fortuito excluya la culpa significaría que él no podría invocarse en casos de responsabilidad objetiva o estricta ${ }^{41}$. Esta circunstancia también ha sido advertida en el extranjero y se ha intentado salvar la cuestión distinguiendo entre caso fortuito y fuerza mayor. Así, en España, un sector de la doctrina y jurisprudencia señalan que el caso fortuito se relaciona con un evento que opera en la esfera interna del sujeto $y$, por tanto, excluye la culpa; la fuerza mayor, en cambio, proviene del externo y, por ende, excluye la causalidad ${ }^{42}$. De esta manera, en hipótesis de responsabilidad objetiva no puede invocarse el caso fortuito, pero sí la fuerza mayor ${ }^{43}$. Algo parecido se observa en Colombia donde, a pesar de la literalidad de la norma, la doctrina y la jurisprudencia, especialmente de carácter administrativo, han hecho esfuerzos por distinguir ambas nociones en el mismo sentido antes dicho ${ }^{44}$.

En Chile, tal distinción se opone al texto legal. En todo caso, más allá de la sinonimia impuesta por el legislador, cuando se analiza la estructura de la responsabilidad desde la perspectiva de la distribución de riesgos, la distinción entre caso fortuito y fuerza mayor no resulta necesaria para extender su aplicación a la responsabilidad objetiva. En efecto, el caso fortuito inicia allí donde termina el ámbito de riesgos atribuible al demandado, afirmación válida tanto para la responsabilidad subjetiva o por culpa, como para la responsabilidad objetiva. La diferencia radica en cómo se determina ese ámbito de riesgos.

En un régimen de responsabilidad subjetiva, el principal factor de delimitación del ámbito de riesgos es justamente la culpa, pues, como afirma Honoré, para que se considere que el hecho 'culpable' del demandado está 'causalmente' conectado con el daño, "el demandante debe probar que el elemento que configura la ilicitud de la conducta (...) fue relevante para la producción del resultado dañoso que da lugar a la acción de responsabilidad" 45 . Existe así una relación funcional entre culpa y causalidad ${ }^{46}$. Esto deriva del hecho de que, desde sus orígenes, la culpa ha servido para dirimir problemas de atribución de responsabilidad frente a una serie de condiciones necesarias para la producción del daño. La culpa permite seleccionar la condición relevante y, así, asignar a la condición 'culpable' el carácter de 'causa' del daño ${ }^{47}$. Esto tiene gran relevancia para el caso fortuito, pues justamente lo que se produce es la concurrencia de dos condiciones necesarias para la producción del daño: el hecho del demandado y el evento que él invoca como fortuito (terremoto, marejada, epidemia, acto de autoridad, etc.), que normalmente será el agente material del daño. De suerte que la pregunta que debe resolver el

\footnotetext{
${ }^{41}$ Esta es justamente la crítica de Pizarro, quien, luego de reseñar la opinión de Domínguez, según la cual en Chile la distinción entre caso fortuito y ausencia de culpa carece de relevancia, pues el caso fortuito excluye la culpa, señala que una opinión semejante solo sería válida en la medida en que se inscribe en la lógica de la ausencia de responsabilidad objetiva. PIZARRO (2005), p. 119. Si bien Pizarro alude a la responsabilidad contractual, el contrapunto con Domínguez hace oportuna la referencia en esta sede, pues la opinión de este último se inserta en una tesis relativa a la relación de causalidad en la responsabilidad extracontractual y fue escrita en los años sesenta, cuando todavía en Chile no adquiría relieve la responsabilidad objetiva.

42 Así, MEDINA (2003), pp. 91 y ss.; REGLERO y BUSTOS (2014), pp. 896 y ss. Con todo, cabe señalar que esta posición, aunque ha tenido algún reconocimiento jurisprudencial, no es pacífica. Así, Díez-Picazo afirma que una distinción semejante solo puede tener cabida en la responsabilidad extracontractual, toda vez que, en esta, dado que la responsabilidad "se funda indiscutiblemente en la culpa, la noción de caso fortuito coincide con la falta de culpa". DíEZ-PICAZO (2008), p. 726. Cabe señalar que este autor es enfático en sostener que la noción de caso fortuito es diferente en sede contractual y extracontractual, aunque en esta última sede no profundiza mayormente el concepto. DíEZ-PICAZO (2011), p. 280.

${ }^{43}$ Sobre el particular, BASOZABAL (2015), pp. 111 y 118. Una aplicación concreta de esta distinción se ha visto en la responsabilidad de la administración que, por aplicación del artículo 106 de la Constitución española, excluiría la posibilidad de invocar el caso fortuito, pero aceptaría la fuerza mayor. La justificación de esta solución se reconduce al hecho de que la responsabilidad administrativa prescindiría de la culpa. RUIZ-TAGLE y COLMAN (2018), pp. y 6 ss.

44 PATIÑO (2008), pp. 198 y ss.

${ }^{45}$ HONORÉ (2016), p. 1079

${ }^{46}$ Aunque no lo expone en los términos que aquí se empelan, cabe señalar que esta relación es advertida por Honoré, cuando, criticando a la doctrina alemana, afirma: "el derecho determina la forma en la cual se enmarca la pregunta acerca de causalidad. En los casos de responsabilidad por culpa, la conexión causal (Kausalzusammenhang en la terminología alemana) no puede ser separadadelaconexiónilegal(oilícita)(Re-chtswidrigkeitszusammenhang); la separación de estos conceptos, planteada por algunos autores alemanes, es una fuente de error". HONORÉ (2016), p. 1079.

${ }^{47}$ Sobre los orígenes de la culpa como criterio para resolver problemas causales en el sentido aquí expuesto, por todos, SAN MARTíN (2017), pp. 50 y ss.; AEDO (2018), pp. 113 y ss., en esta misma obra es posible ver un largo análisis de "las relaciones de la culpa con la causalidad", pp. 385 y ss.
} 
juez es si ¿es posible prescindir jurídicamente del 'evento' y considerar 'causa' del daño al hecho del demandado?

En la generalidad de los casos, la respuesta a esa pregunta puede formularse más o menos en los siguientes términos: el hecho del demandado será 'causa' del daño cuando él sea susceptible de reproche de 'culpa'48. De lo contrario, se acogerá la excepción de caso fortuito y se dirá que 'la causa' del daño fue el 'evento'. Esta última afirmación, sin embargo, no constituye un empleo técnico de la expresión causa. En efecto, en el juicio de atribución de responsabilidad, a diferencia de lo que ocurre en las ciencias y en la filosofía, la pregunta relevante no es 'qué causó el daño', sino si puede afirmarse que él fue 'causado' por el demando ${ }^{49}$. Luego, descartada la posibilidad de condenar al demandado, todo razonamiento respecto de la 'causa efectiva' es jurídicamente intrascendente.

Tal reflexión es consistente con el análisis de la jurisprudencia nacional, la cual acoge la excepción de caso fortuito como una consecuencia de que no puede reprocharse culpa al demandado y viceversa ${ }^{50}$. La función del evento calificado de fortuito es, por tanto, semejante a la función que cumple la culpa exclusiva de la víctima: es un antecedente fáctico para ilustrar la imposibilidad de atribuir responsabilidad al demandado ${ }^{51}$ por estar exento de culpa. La consecuencia práctica de esto es que no corresponde hacer extensiva a la responsabilidad extracontractual la regla del artículo 1547 en cuanto impone la prueba del caso fortuito al demandado, pues lo verdaderamente relevante a efectos del juicio de responsabilidad es si está o no acreditada su culpa ${ }^{52}$.

Cuando la responsabilidad no se funda en la culpa, "lo determinante es que el daño se produzca en el ámbito de riesgo sujeto a responsabilidad estricta" ${ }^{53}$. Así, aquellos eventos que excedan el riesgo que el legislador ha querido dejar de cargo del agente se considerarán casos fortuitos ${ }^{54}$. De esta manera, para exonerarse de responsabilidad, el demandado deberá necesariamente acreditar la ocurrencia de un hecho extraño, que sobrepasa el "fin de protección de la norma" ${ }^{55} \mathrm{y}$, en consecuencia, rompe el nexo de causalidad jurídica entre su conducta y el daño.

En síntesis, no existe ninguna contradicción en señalar que el caso fortuito excluye la culpa $y$, sin embargo, se aplica también a la responsabilidad objetiva. Lo que ocurre es que en ambas formas de responsabilidad el carácter 'imprevisto' del caso fortuito se relaciona con el ámbito

\footnotetext{
${ }^{48}$ Se emplea genéricamente la expresión "susceptible de reproche de culpa", para omitir la discusión respecto de si el juicio de culpabilidad implica o no un análisis subjetivo o si, por el contrario, él es completamente abstracto y objetivo.

${ }^{49}$ HONORÉ (1985), pp. 11 y ss.; CANE (2011), p. 241; STAPLETON (2015), pp. 697 ss.; STEEL (2015), p. 6; PUPPE y WRIGHT (2017), pp. 17 y ss.

${ }^{50}$ A modo de ejemplo, véase Corte Suprema, Rol № 4680-2002, de 27 de noviembre de 2003; Corte Suprema, Rol № 41-2004, de 26 de mayo de 2005, Corte Suprema, Rol № 3151-2007, de 15 de octubre de 2008; Corte Suprema, Rol № 3003-2008, de 4 de noviembre de 2008; Corte Suprema, Rol № 3060-2010, de 18 de octubre de 2010; Corte Suprema, Rol № 217-2010, de 20 de mayo de 2012; Corte Suprema, Rol № 8847-2009, de 18 de octubre de 2012; Corte Suprema, Rol № 9074-2011, de 6 de marzo de 2013; Corte Suprema, Rol № 3864-2011, de 11 de abril de 2013; Corte Suprema, Rol № 2448-2010, de 12 de junio de 2013; Corte Suprema, Rol № 4553-2013, de 7 de mayo de 2014; Corte Suprema, Rol № 7610-2012, de 7 de mayo de 2014; Corte de Apelaciones de Valparaíso, Rol N 1067-2014, de 22 de enero de 2015; Corte Suprema, Rol № 22185-2016, de 17 de mayo de 2017; Corte Suprema, Rol № 10373-2017, de 21 de agosto de 2017; Corte Suprema, Rol № 45850-2016, de 7 de noviembre de 2017; Corte Suprema, Rol № 40703-2017, de 17 de julio de 2019. Si bien no se ventilaron en sede extracontractual, a raíz de la claridad con que evidencian la contraposición entre culpa y caso fortuito, así como la conexión funcional entre culpa y causalidad, resulta oportuno mencionar en esta sede los casos relativos a deterioros en inmuebles con ocasión del $27 \mathrm{~F}$, pues en estos juicios es indiscutido que el terremoto es una conditio sine qua non del daño, de modo que la pregunta que se plantearon los tribunales fue si los edificios se dañaron porque 'estaban mal construidos' o bien su deterioro se produjo 'a raíz del terremoto'. Cada vez que se tuvo por probada una infracción a la lex artis en la construcción (culpa - impericia), el demandado fue considerado 'causante' del daño, en los demás casos estableció que había habido caso fortuito. Corte Suprema, Rol № 4886-2015, de 4 de enero de 2016; Corte Suprema, Rol № 33651-2015, de 10 de marzo de 2016; Corte Suprema, Rol № 16952-2016, de 14 de junio de 2016; Corte Suprema, Rol № 19724-2015, de 30 de diciembre de 2016; Corte Suprema, Rol № 6860-2017, de 13 de noviembre de 2017; Corte Suprema, Rol № 24349-2016, de 25 de enero de 2017; Corte Suprema, Rol № 40703-2017, de 17 de julio de 2019; Corte Suprema, Rol № 1248-2018, de 23 de julio de 2019.

51 SAN MARTíN (2017), pp. 34 y ss.

${ }^{52}$ En tal sentido, Corte Suprema, Rol N 6212-2005, de 11 de septiembre de 2007

${ }^{53}$ BARROS (2006), p. 475.

${ }^{54}$ SÁNCHEZ (2016), p. 289; TRIMARCHI (2017), pp. 351 y ss., especialmente p. 64.

${ }^{55}$ BARROS (2006), p. 475
} 
de riesgos atribuibles al agente, pero esa delimitación es diferente en uno y otro caso. En la responsabilidad subjetiva el factor de atribución y por ende de delimitación del riesgo es la culpa. En la responsabilidad objetiva, en cambio, la delimitación se condice con la finalidad perseguida por la disposición legal que la contempla.

Como refuerzo de las conclusiones anteriores, y por honestidad intelectual, es necesario mencionar que esta forma de ver la institución se encontraba en cierta medida presente en autores franceses de mediados del s. XX, quienes distinguían entre responsabilidad por culpa y por riesgo. En particular, Savatier expresamente afirma que la fuerza mayor o caso fortuito (para él no hay necesidad de distinguir) no funciona igual en caso de que la responsabilidad del agente se funde en la culpa o en el riesgo. Así, afirma, en caso de que la responsabilidad se funde en la culpa, la fuerza mayor se condice con la ausencia de culpa, pero no funciona de la misma manera cuando se trata de responsabilidad por riesgo. Aquí la responsabilidad existe igualmente, aunque no haya culpa, de manera que el caso fortuito o fuerza mayor incide en el riesgo asumido o atribuible al demandado ${ }^{56}$.

Para concluir este apartado, es del caso observar que en este aspecto de la distribución de riesgos conforme a lo que es 'previsto' o 'imprevisto' radica una de las principales diferencias entre el caso fortuito contractual y el extracontractual. En presencia de contrato, la previsión (expresa o tácita) se realiza por las partes al tiempo de celebrar el contrato, distribuyendo entonces los riesgos entre ella, lo que comprende el riesgo de incumplimiento que necesariamente será posterior ${ }^{57}$. En la responsabilidad extracontractual, en cambio, las partes no han tenido ocasión de distribuir sus riesgos con anterioridad al accidente, de ahí que deba atenderse al momento en que este ocurre para determinar 'lo previsto' y proceder a la consecuente distribución de riesgos entre ellas.

\section{La irresistibilidad como elemento del caso fortuito}

\section{La resistibilidad y su conexión con la previsibilidad}

Además del carácter imprevisto, la definición de caso fortuito exige se trate de un 'imprevisto irresistible'. Corresponde, por tanto, establecer qué significa la irresistibilidad y cómo se relaciona este elemento con el hecho de que el caso fortuito excluye la culpa. Al efecto, cabe recordar que desde el Derecho romano la culpa ha tenido dos elementos: la 'previsibilidad' y la posibilidad de adecuar el comportamiento al modelo ideal de conducta ${ }^{58}$. De esta manera, no puede decirse que incurre en culpa quien se enfrenta a un evento que no puede resistir, pues carece de la posibilidad de adecuar su conducta adoptando las medidas para prevenir el daño. La resistibilidad, por tanto, al igual que la previsibilidad, se relaciona con el estándar de conducta que el demandado estaba llamado a observar. Por lo mismo, tampoco puede juzgarse en términos absolutos, sino que debe hacerse en términos relativos, conforme al estándar de diligencia exigible al sujeto concreto ${ }^{59}$.

Como consecuencia de lo anterior, y atendido que en la responsabilidad extracontractual no ha operado entre las partes una distribución de riesgos previa al accidente, la imprevisibilidad tiende a confundirse con la irresistibilidad. En la medida en que el evento no ha sido, ni debía ser previsto por el sujeto como una posible interferencia en su actuación, ciertamente no habrá adoptado las providencias conducentes para impedir su ocurrencia o eludir el daño. En caso

\footnotetext{
${ }^{56}$ SAVATIER (1939), p. 228.

${ }^{57}$ Así las cosas, existe una relación simétrica entre las nociones de previsibilidad contenidas en el artículo 45 y la del artículo 1558. Ambas se refieren a los riesgos que las partes expresa o tácitamente arbitraron al vincularse contractualmente (SAN MARTíN (2014), pp. 649 y ss.). La diferencia radica en "lo previsto". En el artículo 45 se refiere a eventos que impiden al deudor cumplir en tiempo y forma el contrato, mientras que el artículo 1558 alude a los daños que excedan los riesgos asumidos por el deudor como consecuencias posibles de su incumplimiento. En un sentido similar, BRANTT (2011), p. 63 n. 45.

58 Por todos, SAN MARTín (2018), pp. y 556 y ss.

${ }^{59}$ En el mismo sentido, BRANTT (2010), p. 108 y ss.; BRANTT (2011), pp. 55 y ss.; TAPIA (2013), pp. 19 y ss. y TAPIA (2019), pp. 25 y SS.
} 
contrario, el deber de cuidado derivado del principio neminem leadere impone la necesidad de adoptar providencias para evitar el daño o, en última instancia, abstenerse de actuar ${ }^{60}$.

Así las cosas, será caso fortuito aquel evento que el sujeto, conforme a la diligencia exigible (en nuestro caso la del buen padre de familia), estaba llamado a tener en consideración al momento de adoptar la decisión que ahora se cuestiona ('previsto'), adoptando las medidas para evitar la ocurrencia del daño. Por ejemplo, quien construye una muralla en Concepción debe adoptar las medidas que la lex artis impone para el contexto en que actúa ${ }^{61}$ y conforme a las amenazas de eventos destructivos propias de la zona. De esa forma, los vecinos de Concepción no estaban obligados a considerar el tornado del 31 de mayo de 2019 y, por tanto, no tenían el deber de tener casas 'a prueba de tornados' ${ }^{62}$. Por el contrario, sí deben tener en consideración que están situados en una sísmica y, por tanto, sus murallas no pueden amenazar con colapsar y causar daño a terceros en caso de que ocurra un sismo ${ }^{63}$.

Lo dicho hasta aquí corresponde a la responsabilidad fundada en la culpa. En la responsabilidad objetiva o estricta, en cambio, la irresistibilidad no resulta estrechamente ligada al carácter de 'imprevisto' del evento, pues, como ya se dijo, en este caso lo 'previsto' alude a los riesgos que el legislador ha colocado de cargo del agente. Los riesgos 'previstos', entonces, están delimitados a priori y lo imprevisto es todo aquello que excede esta delimitación. La irresistibilidad, por tanto, alude a eventos que, teniendo el carácter de 'imprevistos', son, sin embargo, 'resistibles' para el agente. De este modo, ella viene a ampliar la delimitación del ámbito de riesgos extendiéndola a situaciones que no fueron 'contempladas' al momento de redacción de la norma, pero que el agente está en posición de controlar ${ }^{64}$.

Surge así necesariamente la pregunta relativa al estándar de conducta con que se juzgará la irresistibilidad. Dado que se trata de una responsabilidad objetiva, la primera respuesta que se presenta como una posibilidad es que deberá tratarse de una irresistibilidad 'objetiva' o absoluta, es decir, que ni el agente ni ninguna persona habría podido impedir el daño ${ }^{65}$. Esta respuesta, sin embargo, terminaría por anular la defensa de caso fortuito, pues rara vez estaremos en presencia de un evento de tales características. Así, para darle alguna utilidad a la defensa de caso fortuito en la responsabilidad objetiva, es necesario mesurar el estándar de conducta exigido en la resistibilidad del daño.

Esta cuestión no ha dado lugar a grandes disquisiciones doctrinarias ni jurisprudenciales en el contexto nacional, pues las hipótesis más comunes de responsabilidad objetiva en el derecho extranjero, como son la responsabilidad por accidentes automovilísticos, responsabilidad del Estado, responsabilidad por daño derivados de las cosas, en general, en Chile se resuelven al alero de la culpa, ya sea probada o presunta ${ }^{66}$. No obstante, es posible

\footnotetext{
${ }^{60}$ En efecto, el estándar de cuidado impuesto por la culpa exige a quienes no están en condiciones de respetar ese estándar de abstenerse de actuar, pues la falta de idoneidad para alcanzar el estándar no excluye per se la culpa, esto solo ocurre cuando el sujeto carece de voluntad suficiente para determinar su actuación. SAN MARTín (2018), pp. 556 y ss.

${ }^{61}$ El contexto es relevante, pues no es lo mismo construir una muralla para impedir que se escapen los animales de una casa ubicada en las afueras de la ciudad, que construir una muralla para resguardar el perímetro de un colegio. El estándar de construcción claramente difiere en uno y otro caso.

62 La ocurrencia de un tornado en Concepción, aunque no es la primera vez en la historia que ocurre, claramente no forma parte de los eventos a prever para nadie en la ciudad, y no fueron pocas las casas que perdieron sus techos, con los consecuentes daños para los vecinos sobre cuyas casas cayeron los escombros.

${ }^{63}$ A propósito del 27F, casos semejantes pueden verse en Corte de Apelaciones Valparaíso, Rol № 1458-2012, de 10 de enero de 2013; Corte de Apelaciones de Talca, Rol № 2111-2014, de 7 de septiembre de 2015.

${ }^{64}$ Algo parecido ocurre en materia contractual, pues, dado que la 'previsibilidad' se mira al tiempo de la celebración del contrato, la resistibilidad, en cuanto requisito copulativo, se juzga al momento de la ocurrencia del evento y se refiere exclusivamente a (im)posibilidad de cumplir en tiempo y forma la obligación. De esta manera, la exigencia en forma copulativa de la resistibilidad amplía el ámbito de protección del contrato a riesgos que no fueron previstos por las partes, pero que es posible resistir con la 'diligencia promotora' del cumplimiento. En un sentido similar BRANTT (2011), p. 68.

65 Esto es conforme con el entendimiento tradicional del caso fortuito en sede contractual, para el cual la configuración de la irresistibilidad comporta la "imposibilidad total y absoluta, de modo tal, que nadie ni el deudor ni persona alguna en sus circunstancias habría podido impedirlo". Corte de Apelaciones de Concepción, Rol № 81-2011, de 18 de abril de $2011 ;$ COUSTASSE e ITURRA (1958), p. 116; BARRIENTOS (2016), p. 192.

${ }^{66}$ Salva la hipótesis relativa a los animales fieros del artículo 2327 C.C. En tiempos recientes, existe una inclinación del legislador por la introducción de regímenes de responsabilidad objetiva, aunque la técnica legislativa no siempre permite apreciarlas con claridad. En tal sentido pueden verse Ley № 20.920, de 2016; Ley № 20.850, de 2015; y Ley № 21.020, de 2017.
} 
señalar que en la dimensión de la resistibilidad emerge nuevamente un deber de cuidado o de diligencia conforme a los estándares propios de la actividad desarrollada por el demandado. De manera que, para exonerarse de responsabilidad fundado en caso fortuito, el demandado deberá invocar un acontecimiento extraordinario, en el sentido que excede los riesgos que le impone la norma ('imprevisto') y que él, habiendo desplegado los medios y cuidados propios de su profesión, oficio o actividad, no logró impedir que se tradujera en un daño. Así las cosas, la responsabilidad objetiva resulta no ser tan 'objetiva' como se pretende, pues, también da cuenta de una relación funcional entre culpa y causalidad ${ }^{67}$. La diferencia radica en que el estándar de diligencia es relevante únicamente a efectos de determinar si el sujeto estuvo o no en posibilidad de impedir el daño ocasionado por un evento imprevisto, esto es, que excede el ámbito de riesgos que le impone originalmente la norma, sin que sea relevante a efectos de establecer aquello que el sujeto debió prever.

\section{La distinción entre evento y consecuencias a efectos de calificar la resistibilidad}

Según lo dicho en el apartado anterior, en la responsabilidad extracontractual por culpa no resulta conducente exigir a un sujeto que adopte medidas para 'resistir' algo que no está llamado a prever. Sin embargo, son necesarias algunas precisiones. En efecto, para calificar la resistibilidad del caso fortuito, la doctrina y jurisprudencia nacionales suelen sostener que es necesario distinguir entre el 'evento' que ocasiona el daño y las 'consecuencias' del mismo. Bajo esa distinción, hay quienes afirman que ciertos eventos no pueden ser calificados de casos fortuitos, pero sí sus consecuencias. También se afirma lo contrario, esto es, que el evento constituye un caso fortuito, pero no sus consecuencias.

Así, a propósito del terremoto y sus consecuencias para las construcciones ${ }^{68}$, Pizarro señala que en Chile el terremoto no puede ser calificado de caso fortuito, pues, atendido el carácter sísmico del territorio, "falta el elemento del imprevisto, aunque sea irresistible. Sabemos que puede verificarse, aunque no sabemos cuándo" ${ }^{69}$. Sin embargo, agrega, las constructoras pueden exonerarse de responsabilidad, en razón de que las consecuencias del terremoto sí pueden ser imprevistas e irresistibles, en la medida que se hayan respetado las normas relativas a los estándares de construcción ${ }^{70}$. Sin perjuicio de que concordamos con esta opinión en torno a la irresponsabilidad de las constructoras en estos casos, nos parece que esta forma de presentar el asunto equivale a señalar que el terremoto constituye caso fortuito en la medida que su poder destructivo esté más allá del deber de diligencia o cuidado que pesa sobre el demandado, deber que, tratándose de profesionales de la construcción, estaría delimitado por la normativa antisísmica ${ }^{71}$. En efecto, como todo fenómeno de la naturaleza, a efectos de la responsabilidad civil, el terremoto adquiere relevancia jurídica únicamente cuando genera consecuencias que pueden ser calificadas de daños por los que un tercero-distinto de aquel que las ha padecido- debe responder. Es claro que la constructora nada puede hacer para evitar la ocurrencia de un terremoto de cualquier intensidad, por lo tanto, la pregunta no puede referirse al evento sísmico, sino únicamente a sus consecuencias, esto es, el daño padecido por el demandante. Para ello será esencial determinar si su deber de cuidado alcanzaba la necesidad

\footnotetext{
${ }^{67}$ Esta advertencia la realiza también un autor italiano, quien, luego de haber estudiado la doctrina y jurisprudencia concerniente al caso fortuito en una de las hipótesis clásicas de responsabilidad objetiva en Italia, como es la responsabilidad por daños causados por cosas en custodia, concluye que un aspecto común a toda la doctrina y jurisprudencia es el hecho de que utilizan la dilig encia como parámetro para relativizar el concepto de caso fortuito. PATTI (2019), p. 997. Este autor, sin hablar de relación funcional entre culpa y causalidad, advierte, sin embargo, una superposición entre culpa y causalidad. PATTI (2019), p. 997.

${ }^{68}$ Si bien esta discusión se sitúa en el marco de la responsabilidad de la constructora para con los propietarios, lo que implica aludir a la responsabilidad contractual, la reflexión es válida también en sede extracontractual, por aplicación del artículo 2324 del Código Civil.

69 PIZARRO (2010), p. 174.

70 PIZARRO (2010), pp. 174-175.

${ }^{71}$ En contra de esta opinión está Corral, para quien "el cumplimiento de las Normas chilenas referidas puede considerarse un indicio, aunque no una prueba definitiva y concluyente, de que los daños provocados por el sismo no se han debido a fallas o defectos constructivos". CORRAL (2010b), p. 467.
} 
de implementar medidas conducentes a resistir las consecuencias de un terremoto de las características de aquel que se verificó ${ }^{72}$.

Por otro lado, siempre a propósito de fenómenos naturales extremos, es posible encontrar fallos que contienen el razonamiento contrario al recién planteado. Para estos, en atención a sus características extraordinarias, el fenómeno natural constituye un caso fortuito, pero no sus consecuencias, pues el daño no se debió al fenómeno en sí, sino al hecho de que el demandado no adoptó las medidas necesarias para precaver su ocurrencia y de esta manera evitar sus consecuencias nocivas ${ }^{73}$. Sin perjuicio de que a simple vista este razonamiento parece muy coherente, lo cierto es que, al igual que el anterior, pierde de vista el hecho de que la responsabilidad civil solo se interesa por los hechos o fenómenos naturales en la medida que causen daño: una avalancha en la alta cordillera o un huracán en una isla desierta no presentan problemas de responsabilidad. Asimismo, la cantidad agua caída es irrelevante si de ella no se sigue ninguna inundación u otro tipo de consecuencia dañina. La previsibilidad y resistibilidad, por tanto, deben necesariamente referirse, en el caso, a la inundación, que tiene como presupuesto una gran cantidad de aguas lluvias. En consecuencia, si una determinada cantidad de agua era imprevisible, imprevisible e irresistible eran también las consecuencias de las mismas. Sostener lo contrario implica juzgar con el conocimiento ex post una decisión que el sujeto debía tomar ex ante. Así las cosas, en principio, no resulta oportuno distinguir entre hecho y consecuencias como dos aspectos independientes.

Con todo, lo anterior no significa que la distinción entre evento y consecuencias no tenga alguna relevancia jurídica, pero su planteamiento requiere de elementos adicionales. Es necesario distinguir entre consecuencias concomitantes y posteriores al evento.

Tratándose de las consecuencias que se generan de manera concomitante al evento o inmediatamente después, la distinción entre ambos conceptos cobra gran relevancia a efectos de sostener que el daño hubiese tenido lugar incluso en presencia de un evento que no revistiera las características de fortuito. También es relevante la distinción cuando las consecuencias en sí mismas consideradas aparezcan anómalas en relación al evento que las ocasionó. Esta última hipótesis generalmente implica una causa adicional, lo que genera la dificultad relativa a la admisibilidad de la concurrencia causal entre condiciones humanas y naturales, aspecto que no es posible abordar en esta sede ${ }^{74}$.

Una cuestión distinta se produce con las consecuencias posteriores al evento. Ellas se independizan de su fuente $y$, por tanto, deben ser sometidas a un test autónomo de previsibilidad y resistibilidad: $s i$, a raíz del terremoto, se debilita ostensiblemente una muralla, que meses, o incluso días, después se derrumba sobre un transeúnte, no cabe hablar de caso fortuito, por mucho que sin la ocurrencia del terremoto la muralla no se hubiese caído.

\section{Conclusiones}

Como conclusión principal, es posible señalar que, independientemente del régimen de responsabilidad, el caso fortuito implica un hecho que está más allá del ámbito de riesgos atribuibles al demandado. La diferencia fundamental entre los regímenes radica en la forma en que se delimita ese ámbito de riesgos. En la responsabilidad contractual, lo define el contrato. En la extracontractual, hay que distinguir entre la responsabilidad por culpa y responsabilidad estricta u objetiva. En el primer caso el principal factor de delimitación es justamente la culpa: solo se responde por los daños generados con culpa. En el segundo caso, lo define el fin perseguido por el legislador con la introducción de la hipótesis de responsabilidad objetiva.

\footnotetext{
72 En efecto, así han sido resueltos los casos relativos a los deterioros de inmuebles con ocasión del $27 \mathrm{~F}$. Véase antes, nota 50.

${ }^{73}$ En tal sentido, Corte Suprema, Rol № 8847-2009, de 18 de octubre de 2012; Corte Suprema, Rol № 22185-2016, de 17 de mayo de 2017.

${ }^{74}$ Con todo, cabe señalar que el entendimiento de la jurisprudencia, así como de la mayoría de la doctrina chilena, es que no es posible la concurrencia causal entre el 'caso fortuito' y la culpa del demandado, por tratarse de una eximente total de responsabilidad. Por todos, SAN MARTín (2019), pp. 132 y ss.
} 
Asimismo, a modo de conclusiones generales, es oportuno sintetizar las respuestas dadas a las tres preguntas planteadas al inicio de este texto:

1. La sinonimia entre caso fortuito y fuerza mayor. De la conclusión principal se desprende que no es necesario distinguir entre caso fortuito y fuerza mayor a efectos de hacer extensiva la eximente a la responsabilidad objetiva. Es perfectamente posible mantener la sinonimia entre ambas nociones.

2. Si el caso fortuito incide en la culpa o la causalidad. La respuesta no es blanco o negro, sino en escala de grises, pues implica reconocer la relación funcional entre culpa y causalidad. En la responsabilidad subjetiva, en la medida que la previsibilidad y la resistibilidad son elementos de la culpa, el caso fortuito excluye a este elemento. Además, atendida la relación funcional entre culpa y causalidad, excluye, en consecuencia, a la causalidad. En la responsabilidad objetiva, el caso fortuito incide directamente en la causalidad.

3. En cuanto a la relación entre imprevisibilidad e irresistibilidad. Ambas nociones están interconectadas, lo que es especialmente válido para la responsabilidad fundada en la culpa. En efecto, tanto la imprevisibilidad (mejor dicho, el carácter imprevisto) como la irresistibilidad aluden a un estándar de conducta que se condice con la idea de buen padre de familia (persona razonable) y, por ende, implican la ausencia de culpa. Sin embargo, el carácter imprevisto, se relaciona con la idea de ámbito de protección y, por tanto, con la distribución de riesgos propia de la responsabilidad civil. En la responsabilidad extracontractual, dado que entre las partes no ha operado una distribución negociada de riesgos con anterioridad al accidente, la irresistibilidad tiende a coincidir con la imprevisibilidad: no es posible resistir aquello que no se ha previsto.

Esa situación es ligeramente distinta en sede de responsabilidad objetiva. En este caso existe una distribución de riesgos ex ante determinada por el fin o ámbito de protección de la norma. De manera que lo 'imprevisto' serán los riesgos que exceden a aquellos que el legislador coloca de cargo del agente, mientras que lo 'irresistible' será aquello que, con el cuidado ordinario propio de su actividad, profesión u oficio, él no estaba en condiciones impedir o eludir.

\section{BIBLIOGRAFÍA CITADA}

Aedo BarRena, Cristian EduARDo (2018): Culpa aquiliana. Una conjunción de aspectos históricos y dogmáticos (Santiago, Thomson Reuters).

Alarcón González, Victoria ANDREa y MuÑOZ BRUNA, FranCISCA ISIDORA (2018): Análisis jurisprudencial sobre la responsabilidad civil extracontractual del estado por falta de servicio derivada del terremoto y posterior tsunami del 27F. Memoria para optar al Grado de Licenciadas en Ciencias Jurídicas y Sociales (Santiago, Facultad de Derecho Universidad de Chile, no publicada).

ALESSANDRI RodRÍGUEZ, ARTURo (2005): De la responsabilidad extracontractual en el derecho civil chileno, reimpresión (Santiago, Editorial Jurídica de Chile).

Amunátegui Perelló, Carlos (2019): Código Civil de Chile. Edición anotada, concordada y con fuentes (Santiago, Tirant lo Blanch).

BARRÍA DíAZ, RodRIGo (2019): "La pérdida de una oportunidad en la jurisprudencia de la Corte Suprema sobre juicios indemnizatorios derivados del terremoto y tsunami de 27 de febrero de 2010", en: Revista de Derecho - Concepción (Vol. 87, № 245), pp. 235-269.

Barrientos Grandon, Javier (2016): El Código Civil. Su jurisprudencia e historia (Santiago, Thomson Reuters), tomo I.

Basozabal Arrue, Xavier (2015): Responsabilidad extracontractual objetiva: parte general (Madrid, Agencia Estatal Boletín Oficial del Estado). 
Bello, ANDRÉs (1890): Proyecto inédito de Código Civil. Edición hecha bajo la dirección del Consejo de Instrucción Pública en cumplimiento de la Lei de 5 de Setiembre de 1872 (Santiago, Pedro G. Ramírez).

BINDER, DENIS (1996): "Act of God? or Act of Man?: A Reappraisal of the Act of God Defense in Tort Law", en: The Review of Litigation (Vol. 5, № 1), pp. 1-79.

BRANTt ZUMARÁN, MARía Graciela (2009): "La exigencia de exterioridad en el caso fortuito: Su construcción a partir de la distribución de los riesgos del contrato", en: Revista de Derecho de la Pontificia Universidad Católica de Valparaíso (Vol. XXXIII), pp. 39-102.

(2010): El caso fortuito y su incidencia en el derecho de la responsabilidad civil contractual (Santiago, AbeledoPerrot - Legal Publishing).

(2011): “El caso fortuito: concepto y función como límite de la responsabilidad contractual”, en: Cuadernos de Análisis Jurídico, Universidad Diego Portales (№ VII), pp. 47-82.

BRUN, PHILIPPE (2015): Responsabilidad extracontractual (Traducc. Cinthya Téllez Gutiérrez y Eduardo Cárdenas Miranda, Lima, Instituto Pacífico).

CANe, Peter (2011): Anatomía del derecho de daños (Traducc. Daniel Arturo Carvallo Montes y Pablo Andrés Becerra Poblete, Santiago, Flandes Indiano).

CANNATA, CARLO AUgusto (1992): "Sul problema della responsabilità nel diritto privato romano", en: IVRA (XLIII), pp. 1-82.

CARDILLI, RICCARDO (1995): L'obbligazione di "praestare" e la responsabilità contrattuale in diritto romano (Milán, Giuffrè Editore).

(1996): “Il ruolo della 'dottrina' nella elaborazione del 'sistema': I'esempio della 'responsabilità contrattuale'”, en: Roma e America (№ 1), pp. 79-113.

CLARO SOLAR, LUIS (2015): Explicaciones de derecho civil chileno y comparado (reimpresión Santiago, Editorial Jurídica de Chile), volumen I.

Colegio de Abogados de Chile (2010): "Revista del Abogado (№ 48)". Disponible en: https://bit.ly/2P1sSeO [visitado el 30 de marzo de 2020].

Corral TAlCIANI, Hernán (2010a): "El caso fortuito como causa de exoneración de la responsabilidad contractual”, en: Corral Talciani, Hernán, Contratos y daños por incumplimiento (Santiago, Abeledo Perrot - Legal Publishing), pp. 131-139.

(2010b): "Responsabilidad civil en la construcción de viviendas. Reflexiones sobre los regímenes legales aplicables a los daños provocados por el terremoto del 27 de febrero de 2010", en: Revista Chilena de Derecho (Vol. 37, №3), pp. 459-475.

(2013): Lecciones de responsabilidad civil extracontractual, 2a edición (Santiago, Legal Publishing - Thomson Reuters).

Coustasse, Alberto Del C. E Iturra, Fernando A. (1958): El caso fortuito ante el derecho civil (Santiago, Editorial Jurídica de Chile).

De NARDI, LoRIS (2019): "Secularizar el desastre. El artículo 45 del código civil chileno de 1855", en: Revista de Historia del Derecho (№ 58), pp. 59-78.

DelvincourT, M. (1834): Cours de Code Civil (Dijon - París, Victor Lagier Libraire - Videcoq Libraire), volumen II.

DíEZ-PICAZO, LUIS (2008): Fundamentos del derecho civil patrimonial II. Las relaciones obligatorias, 6a edición (Madrid, Thomson Reuters - Civitas). 
(2011): Fundamentos del derecho civil patrimonial V. La responsabilidad extracontractual (Madrid, Thomson Reuters - Civitas).

DoneluI, HugonIS (1764): “Commentaoriorum de luri Civili, ad. Lib. XVI, Cap. VI, n. XII", en: Donelli, Hugonis, Opera omnia (Lucca, Joannis Riccomini), tomo IV.

ESCRICHE, JOAQUín (1831): Diccionario razonado de legislación civil, penal, comercial y forense, o sea Resumen de las leyes, usos, prácticas y costumbres, como así mismo de las doctrinas de los jurisconsultos, (París, Imprenta de P. Dupont y G. Laguionie), tomo II.

Farfarello Galletti, Antonella (2019): Responsabilidad del Estado. Terremoto del 27 de febrero de 2010 (Santiago, Rubicón Editores).

FeRRARIS, F. LUCII (1861): “Voz 'Culpa'”, en: Ferraris, F. Lucii, Prompta biblioteca, 9a edición (Parí, J.P. Migne), tomo 2.

Franco leguízamo, Camilo Armando (2009): "Caleidoscopio de la fuerza mayor (derecho comparado e internacional)", en: Revista e-Mercatoria (Vol. 8, № 1), pp. 1-51.

GARCíA GoYeNA, FLORENCIO (1852): Concordancias, motivos y comentarios del Código civil español (Madrid, Abienzo), tomo III.

Gianfelici, Mario CeSAR (1995): Caso fortuito y caso de fuerza mayor (Buenos Aires, AbeledoPerrot).

HART, H.L.A. Y HONORÈ, TONY (1985): Causation in the Law, 2a edición (Oxford, Clarendon Press).

HINESTROSA, FERNANDO (2007): Tratado de las obligaciones. Concepto, estructura, vicisitudes, 3aㅡ edición (Bogotá, Universidad Externado de Colombia), tomo I.

HONORÉ, TONY (2016): “Condiciones necesarias y suficientes en la responsabilidad extracontractual, (Traducc. Arturo Ibáñez León y Alberto Pino Emhart)", en: Revista Chilena de Derecho (Vol. 40, № 3), pp. 1073-1097.

LETELIER WARTENBERG, RAÚL (2001): La fuerza mayor en la responsabilidad extracontractual de la administración del Estado (Santiago, Conosur - LexisNexi).

Mazeaud, Henri; Mazeaud, Lèon y Mazeaud, Jean (1960): Lecciones de derecho civil. Parte segunda. La responsabilidad civil. Los cuasicontratos (Traducc. Luis Alcalá-Zamora y Castillo, Buenos Aires, Ediciones Jurídicas Europa-América), volumen II.

MEDINA ALCOZ, MARía (2003): La culpa de la víctima en la producción del daño extracontractual (Madrid, Dykinson).

MUNITA MARAMBIO, RENZO (2014): "La fuerza mayor y sus interrogantes conceptuales. Un análisis desde la perspectiva del derecho francés de la responsabilidad civil", en: Revista Actualidad Jurídica (№ 30) pp. 393-442.

PATIÑO, HÉCTOR (2008): "Responsabilidad extracontractual y causales de exoneración. Aproximación a la jurisprudencia del Consejo de Estado colombiano", en: Revista de Derecho Privado, Universidad Externado de Colombia (№ 14), pp. 193-217.

PATTI, FRANCESCO PAOLO (2019): “Il declino della responsabilità oggettiva (a margine dell'art. 2051 c.c.)", en: Revista de Diritto Civile (№ 4/2019), pp. 977-1013.

PizarRo Wilson, Carlos (2005): "La fuerza mayor como defensa del deudor. A propósito de la restricción de suministro de gas a Chile", en: Revista de Derecho Administrativo (№ 14), pp. 115124.

(2010): "Daños en la construcción, fuerza mayor y terremotos", en: Revisa de Derecho de la Pontificia Universidad Católica de Valparaíso (Vol. XXXIX), pp. 161-176. 
PLANIOL, MARCELO Y RIPERT, JORGE (1946): Tratado práctico de derecho civil francés (Traducc. Mario Díaz Cruz, La Habana, Cultural S.A.).

Puppe, INGeBorg Y WRIGHT, RiChARD W. (2017): "Causation in the Law. Philosophy, Doctrine and Practice", en: Infantino, Marta y Zervogianni, Elena (Eds.), Causation in European Tort Law (Cambridge, Cambridge University Press).

Reglero Campos, Fernando y Bustos Lago, José Manuel (2014): Tratado de responsabilidad civil, 5a edición (Madrid, Aranzadi Thomson Reuters), tomo I.

Ríos ERAZO, IgNACIO (2017): Incerteza Causal en la Responsabilidad Civil. Jurisprudencia terremoto del 27 de febrero de 2010. Tesis para optar al grado de Magíster en derecho con mención en Derecho Privado (Santiago, Facultad de Derecho, Universidad de Chile Santiago, no publicada).

Rodríguez GReZ, PABLo (2010): Responsabilidad extracontractual, 2ª edición (Santiago, Editorial Jurídica de Chile).

RUIZ-TAgle Vial, CARLos y Colman Vega, LUIS (2018): "Regímenes de amparo y cobertura de los desastres naturales en el derecho español", en: Revista Boliviana de Derecho (№ 25), pp. 376415.

SAN MARTín NeIRA, LILIAN C. (2014): "La previsibilidad como límite al resarcimiento del daño por incumplimiento contractual”, en: Turner, Susan y Varas, Juan Andrés (Eds.), Estudios de Derecho Civil IX (Santiago, Legal Publishing - Thomson Reuters), pp. 649-668.

(2017): La culpa de la víctima en la responsabilidad civil (Santiago, Der Ediciones).

(2018): "La imputabilidad o capacidad como elemento de la responsabilidad civil extracontractual. Un debate pendiente en la doctrina chilena", en: Revista lus et Praxis (Año 24, № 1), pp. 553-592.

(2019): “Desastres naturales y responsabilidad civil. Identificación de los desafíos que presenta esta categoría de hechos dañinos", en Revista de Derecho - Valdivia (Vol. XX XII№ 2), pp. 123-142.

SÁnChez HeRnández, LUis CARlos (2016): "De la culpa de la lex Aquilia del derecho romano al principio de la responsabilidad por culpa en el derecho civil colombiano", en: Revista de Derecho Privado, Universidad Externado de Colombia (№ 30), pp. 287-335.

SAVATIER, Rènè (1939): Traité de la responsabilité civile en Droit français. Les sources de la responsabilité civile (Paris, Librarie Générale de Droit et Jurisprudence), tomo I.

SCHOPF OlEA, AdRIÁN (2017): "Las diferencias funcionales entre la responsabilidad civil contractual y extracontractual", en: A.A.V.V, Presente y futuro de la responsabilidad civil (Santiago, Thomson Reuters), pp. 61-86.

SERRANO-VICENTE, MARTín (2006): Custodiam praestare: la prestación de custodia en el derecho romano (Madrid, Tebar).

Stapleton, JANe (2015): "An 'extended But-For Test for the Causal Relation in the Law of Obligations", en: Oxford Journal of Legal Studies (Vol. 35, № 4), pp. 697-726.

SteEL, SANDy (2015): Proof of Causation in Tort Law (Cambridge, Cambridge University Press).

TAPIA Rodríguez, MAURICIO (2013): Caso fortuito en el derecho civil chileno (Santiago, Legal Publishing - Thomson Reuters).

(2019): Caso fortuito o fuerza mayor, 2a edición (Santiago, Thomson Reuters).

TRIMARCHI, PIETRO (2017): La responsabilità civile: atti illeciti, rischio, danno (Milán, Giuffrè Editore). 
VINNIO, ARNoldo (1847): Comentario académico y forense (Traducc. D. I. P. y B., Barcelona, Establecimiento Tipográfico de Juan Olivers de S. M.), tomo II.

JURISPRUDENCIA CITADA

VeRGARA CON I. MUNICIPALIDAD DE CONCEPCIÓN (2003): Corte Suprema 27 de noviembre de 2003 (casación fondo), Rol № 4680-2002, en: www.pjud.cl

BAEZa CON MUNICIPALIDAd DEL VIÑa Del MAR (2005): Corte Suprema 26 de mayo de 2005 (casación forma y fondo), Rol № 41-2004, en: www.pjud.cl

SAHURIE CON JAHUEL INGENIERÍA (2007): Corte Suprema 11 de septiembre de 2007 (casación fondo), Rol № 6212-2005, en: www.pjud.cl

SieRRA CON I. MUNICIPALIDAD DE CONCEPCIÓN (2008): Corte de Apelaciones de Concepción 8 de abril de 2008 (recurso de apelación), Rol № 940-2007, en: www.pjud.cl

MANRÍQUEZ CON FISCO (2008): Corte Suprema 15 de octubre de 2008 (casación fondo), Rol № 3151-2007, en: www.pjud.cl

SierRa CON I. MuniCiPALIDAD DE CONCEPCIÓN (2008): Corte Suprema 4 de noviembre de 2008 (casación fondo), Rol № 3003-2008, en: www.pjud.cl

VARGAS CON FISCO (2010): Corte Suprema 18 de octubre de 2010 (casación fondo), Rol № 30602010, en: www.pjud.cl

SANDOVAL CON MuÑoz (2012): Corte Suprema 20 de mayo de 2012 (casación fondo), Rol № 2172010, en: www.pjud.cl

GARRID CON FISCO (2012): Corte Suprema 18 de octubre de 2012 (casación fondo), Rol № 88472009, en: www.pjud.cl.

BRAVO CON DROPPELMANN (2013): Corte de Valparaíso 10 de enero de 2013 (recurso de apelación), Rol № 1458-2012, en: www.pjud.cl

CLAVERIE CON Fisco (2013): Corte Suprema 6 de marzo de 2013 (casación fondo), Rol № 90742011, en: www.pjud.cl

MülLeR CON CoOperativa ElÉCTRICA de CHILLÁN (2013): Corte Suprema 11 de abril de 2013 (casación fondo), Rol № 3864-2011, en: www.pjud.cl

Danke CON The Conservation LAND TRUSt (2013): Corte Suprema 12 de junio de 2013 (casación fondo), Rol № 2448-2010, en: www.pjud.cl

GAVILÁn CON Forestal CelCo (2014): Corte Suprema 7 de mayo de 2014 (casación forma y fondo), Rol № 7610-2012, en: www.pjud.cl

MülLeR CON COOPERATIVA ELÉCTRICA DE CHILLÁN (2014): Corte Suprema 7 de mayo de 2014 (casación forma y fondo), Rol № 4553-2013, en: www.pjud.cl

SelAme CON SOCIEDAD CRI S.A. (2015): Corte de Apelaciones de Valparaíso 22 de enero de 2015 (apelación), Rol N 1067-2014, en: www.pjud.cl

BALTERA CON INMOBILIARIA PAZ LTDA. (2015): Corte de Talca 7 de septiembre de 2015 (apelación), Rol № 2111-2014, en: www.pjud.cl

CoRPoración AdMinistrativa del Poder Judicial CON COMANDEF (2016): Corte Suprema 4 de enero de 2016 (casación fondo), Rol № 4886-2015, en: www.pjud.cl

ORTIZ CON INMOBILIARIA DON CRISTÓBAL S.A. (2016): Corte Suprema 10 de marzo de 2016 (casación fondo), Rol № 33651-2015, en: www.pjud.cl 
TORRES CON I. MUNICIPALIDAD DE HUALPÉN (2016): Corte Suprema 14 de junio de 2016 (casación forma y fondo). Rol № 16952-2016, en: www.pjud.cl

PÉREZ CON VIVIENDAS 2000 LTDA. (2016): Corte Suprema 30 de diciembre de 2016 (casación fondo), Rol № 19724-2015, en: www.pjud.cl

Cáceres con Inmobiliaria San Pedro del Valle (2017): Corte Suprema 25 de enero de 2017 (casación fondo), Rol № 24349-2016, en: www.pjud.cl

QUEZADA CON FISCO (2017): Corte Suprema 17 de mayo de 2017 (casación forma y fondo), Rol № 22185-2016, en: www.pjud.cl

Aspillaga con SAUVAgeot (2017): Corte Suprema 21 de agosto de 2017 (casación fondo), Rol № 10373-2017, en: www.pjud.cl

URRUTIA CON ESVAL S.A. (2017): Corte Suprema 7 de noviembre de 2017 (casación forma y fondo), Rol № 45850-2016, en: www.pjud.cl

BASTías CON FISCO (2017): Corte Suprema 13 de noviembre de 2017 (casación fondo), Rol № 68602017, en: www.pjud.cl

Universidad de Talca con Constructora Marcelo Rivano (2019): Corte Suprema 17 de julio de 2019 (casación forma y fondo), Rol № 40703-2017, en: www.pjud.cl

SÁNCHEZ CON INMOBILIARIA MIRAMAR (2019): Corte Suprema 23 de julio de 2019 (casación forma), Rol № 1248-2018, en: www.pjud.cl

\section{NORMAS JURÍDICAS CITADAS}

Código CIVIL DE CHILE.

LEY № 20.850, que crea un sistema de protección financiera para diagnósticos y tratamientos de alto costo y rinde homenaje póstumo a don Luis Ricarte Soto Gallegos. Diario oficial, 6 de junio de 2015.

LEY № 20.920, que establece marco para la gestión de residuos, la responsabilidad extendida del productor y fomento al reciclaje. Diario Oficial, 1 de junio de 2016.

LEY № 21.020, establece normas sobre tenencia responsable de mascotas y animales de compañía. Diario oficial, 2 de agosto de 2017. 